\title{
APLIKASI LAPORAN KEBAKARAN DAN PENYELAMATAN KANTOR PEMADAM KEBAKARAN SEKTOR VI KECAMATAN MAKASAR
}

\author{
Ahmad Fauzi ${ }^{1}$, Nur Alamsyah ${ }^{2}$ \\ 1,2Teknik Informatika, Fakultas Teknik dan Ilmu Komputer, Universitas Indraprasta PGRI Jakarta \\ Jalan Raya Tengah No 80, Kelurahan Gedong, Pasar Rebo, Jakarta Timur \\ 1fauzi08960@gmail.com, $\underline{2 \text { alamcbr11@gmail.com }}$
}

\begin{abstract}
ABSTRAK
Permasalahan yang terdapat pada Kantor Pemadam Kebakaran Sektor VI Kecamatan Makasar yaitu Dalam proses input data pegawai, presensi, data kegiatan kebakaran dan penyelamatan masih ada yang dilakukan secara manual sehingga pencarian data pegawai, data presensi, data kegiatan kebakaran dan penyelamatan membutuhkan waktu yang lama dan tidak efektif karena sistem yang ada masih manual kemudian mencari data yang dibutuhkan, pencarian dilakukan di arsip. Sistem informasi yang belum terkomputerisasi menyebabkan admin menjadi terhambat dan kurang efisien. Tujuan merancang suatu aplikasi laporan kebakaran dan penyelamatan ini dengan tujuan untuk memudahkan admin dalam memproses pengolahan data yang ada saat ini. Perangkat aplikasi yang telah dibuat dengan bahasa pemrograman Java NetBeans 8.0.2 dan penyimpanan data pada database MySQL dapat memberikan kelancaran dalam proses menginput dan penyimpanan data-data serta laporan-laporan yang diberikan kepada pemilik apotik. Dengan menggunakan metode pengembangan sistem yaitu Waterfall dalam penelitian ini adalah dengan tahapan-tahapan seperti rekayasa sistem, analisis, desain, coding, testing, dan maintenance. Hasil dari penelitian ini menciptakan suatu sistem informasi yang mudah dipahami oleh bagian admin agar mudah digunakan oleh setiap pegawai yang ada pada Kantor Pemadam Kebakaran Sektor VI Kecamatan Makasar.
\end{abstract}

Kata Kunci: Aplikasi, Laporan, Kebakaran, Penyelamatan, Desktop

\begin{abstract}
The problems found in the Sector VI Fire Department, Makasar District, are in the process of inputting employee data, attendance, fire and rescue activity data, which are still done manually so that the search for employee data, attendance data, fire and rescue activity data takes a long time and does not require a lot of time. effective because the existing system is still manual then look for the data needed, the search is done in the archive. The information system that has not been computerized causes the admin to be hampered and less efficient. The purpose of designing a fire and rescue report application is to make it easier for admins to process the current data processing. Application tools that have been created using the Java NetBeans 8.0.2 programming language and data storage in the MYSQL database can provide a smooth process for inputting and storing data and reports provided to the pharmacy owner. By using the system development method, namely Waterfall, in this research, the stages are systems engineering, analysis, design, coding, testing, and maintenance. The results of this study create an information system that is easily understood by the admin section so that it is easy to use by every employee in the Sector VI Fire Department, Makasar District.
\end{abstract}

Key Word: Application, Report, Fire, Rescue, Desktop

\section{PENDAHULUAN}

Perkembangan ilmu teknologi dan informasi yang berkembang saat ini sangat pesatnya sehingga membuat kita untuk tidak ketinggalan mengikuti kemajuan teknologi informasi. Kemajuan tersebut menghasilkan manfaat yang baik untuk mendorong percepatan berbagai bidang, termasuk lembaga dan instansi. Seiring dengan perkembangan teknologi yang begitu pesat, kebutuhan akan informasi sangat diperlukan, sehingga mempermudah pengguna (user) dalam melakukan suatu pekerjaan (Antisipasi \& Jakarta, 2016).

Kantor Pemadam Kebakaran Sektor VI Kecamatan Makasar beralamat di Jl. Kamboja No.19, RT.10/RW.1, Kb. Pala, Kec. Makasar, Kota Jakarta Timur, Daerah Khusus Ibukota Jakarta 13650 merupakan instansi pemerintahan 
yang bertugas dalam pemadaman kebakaran dengan ruang lingkup Kecamatan Makasar (Kebakaran, Kowara, Martiana, \& Keselamatan, 2017). Akan tetapi pengolahan data laporan kegiatan kebakaran dan penyelamatan tiap bulan masih dicatat dalam sebuah buku khusus, dan untuk menyerahkan bukti laporan data kegiatan kebakaran dan penyelamatan masih bersifat konvensional (Fitriansyah, 2017). Masalah yang timbul adalah ketidakkonsistensian data yang dapat menyebabkan kerangkapan data, apabila dalam pencarian data membutuhkan waktu yang sangat lama karena masih menggunakan sistem yang konvensional,dan keamanan data pun masih kurang terjamin (Arrazy, Sunarsih, \& Rahmiwati, 2014).

Dengan permasalahan tersebut, perlu ada nya suatu sistem yang terkomputerisasi dalam penyelesaiannya. Sistem adalah sekelompok unsur yang erat hubungannya satu dengan yang lain, yang berfungsi bersama-sama untuk mencapai tujuan (Sutabri, 2012). Sistem merupakan suatu kumpulan dari komponenkomponen yang membentuk satu kesatuan (Tyoso, 2016). Pembangunan sistem adalah sekumpulan aktivitas yang menggambarkan secara rinci bagaimana sistem akan berjalan. Hal itu bertujuan untuk menghasilkan produk perangkat lunak yang sesuai dengan kebutuhan user (Satzinger, J. W., Jackson, R. B., Burd, n.d.).

Diharapkan dengan adanya suatu sistem informasi dapat menangani permasalahan yang ada di perusahaan tersebut. Sistem adalah setiap sesuatu terdiri dari obyek-obyek, atau unsur-unsur, atau komponen-komponen yang bertata kaitan dan bertata hubungan satu sama lain, sedemikian rupa sehingga unsur-unsur tersebut merupakan satu kesatuan pemrosesan atau pengolahan yang tertentu. (Prasojo, 2011)

Aplikasi ini dapat memudahkan pekerjaan Admin Perusahaan dalam melaksanakan pembuatan laporan dan mempercepat dalam proses data pencarian data laporan kegiatan dan penyelamatan pada Kantor Pemadam Kebakaran Sektor VI Kecamatan Makasar.

\section{METODE PENELITIAN}

Peneliti menggunakan metode Research and Development daam penyelesaian penelitian ini. (Sugiyono, 2016). Dalam pelaksanaan R\&D, ada beberapa metode yang digunakan yaitu metode deskriptif, evaluatif dan eksperimental. Metode penelitian deskriptif digunakan dalam penelitian awal untuk menghimpun data tentang kondisi yang ada yaitu penulis membutuhkan data-data yang dapat menunjang terciptanya suatu sistem informasi laporan kegiatan kebakaran dan penyelamatan di Kantor Pemadam Kebakaran Sektor VI Kecamatan Makasar seperti data pegawai, data kebakaran, data korban kebakaran, dan data penyelamatan terdahulu yang masih tersimpan secara manual didalam buku besar. Metode evaluatif digunakan untuk mengevaluasi proses ujicoba pengembangan suatu produk, dalam proses ini penulis melakukan ujicoba terhadap suatu sistem yang telah dirancang agar tidak ada terjadi kesalahan dalam proses penginputan data serta pelaporan bulanan kepada Kepala Seksi Sektor VI Makasar. Dan metode eksperimen digunakan untuk menguji keampuhan dari produk yang dihasilkan, dalam proses yang terakhir ini perlu dilakukan pengujian akhir yang diharapkan bahwa sistem yang dirancang oleh penulis dapat berjalan dengan baik dan sesuai dengan kebutuhan dan terfokus pada proses pengolahan laporan kegiatan kebakaran dan penyelamatan di Kantor Pemadam Kebakaran Sektor VI Kecamatan Makasar (Putra, 2011).

\section{HASIL DAN PEMBAHASAN Analisa Permasalahan}

Pada sistem informasi laporan kegiatan kebakaran dan penyelamatan pada Kantor Pemadam Kebakaran Sektor VI Kecamatan Makasar ini ternyata mempunyai beberapa kelemahan karena sistem yang digunakan belum sepenuhnya terkomputerisasi.

1. Dalam proses input data pegawai, presensi, data kegiatan kebakaran dan penyelamatan masih ada yang dilakukan secara manual.

2. Pencarian data pegawai, data presensi, data kegiatan kebakaran dan penyelamatan membutuhkan waktu yang lama dan tidak efektif karena sistem yang ada masih manual sehingga jika mencari data yang dibutuhkan, pencarian dilakukan di arsip. 
3. Sistem informasi yang belum terkomputerisasi menyebabkan admin menjadi terhambat dan kurang efisien.

4. Kurangnya sumber daya manusia yang memahami sistem komputerisasi.

5. Pembuatan laporan data pegawai, data presensi, data kegiatan kebakaran dan penyelamatan yang dilakukan secara manual memungkinkan terjadinya kesalahan data dan membutuhkan waktu yang lama dalam memperbaikinya.

\section{Alternatif Penyelesaian Masalah}

Untuk mencari solusi dalam permasalahan yang ada maka penulis membuat suatu sistem yang akan membantu dalam menyelesaikan masalah tersebut. Berdasarkan analisa sistem yang sedang berjalan saat ini penulis melihat beberapa kelemahan dan pokok permasalahan yang terdapat pada sistem informasi laporan data kegiatan kebakaran dan penyelamatan pada Kantor Pemadam Kebakaran Sektor VI Kecamatan Makasar di atas, maka penulis memberikan saran beberapa alternatif penyelesaian masalah diantaranya:

1. Merancang sistem informasi terkomputerisasi yang dapat membantu dalam data pegawai, data presensi, data kegiatan kebakaran dan penyelamatan.

2. Perancangan database untuk sistem sehingga penyimpanan data tidak menggunakan media kertas lagi.

3. Data yang ada disimpan ke hardisk dan membuat backup-an data.

4. Membuat sistem informasi yang mudah dipahami oleh bagian admin agar mudah digunakan oleh setiap pegawai yang ada pada Kantor Pemadam Kebakaran Sektor VI Kecamatan Makasar.

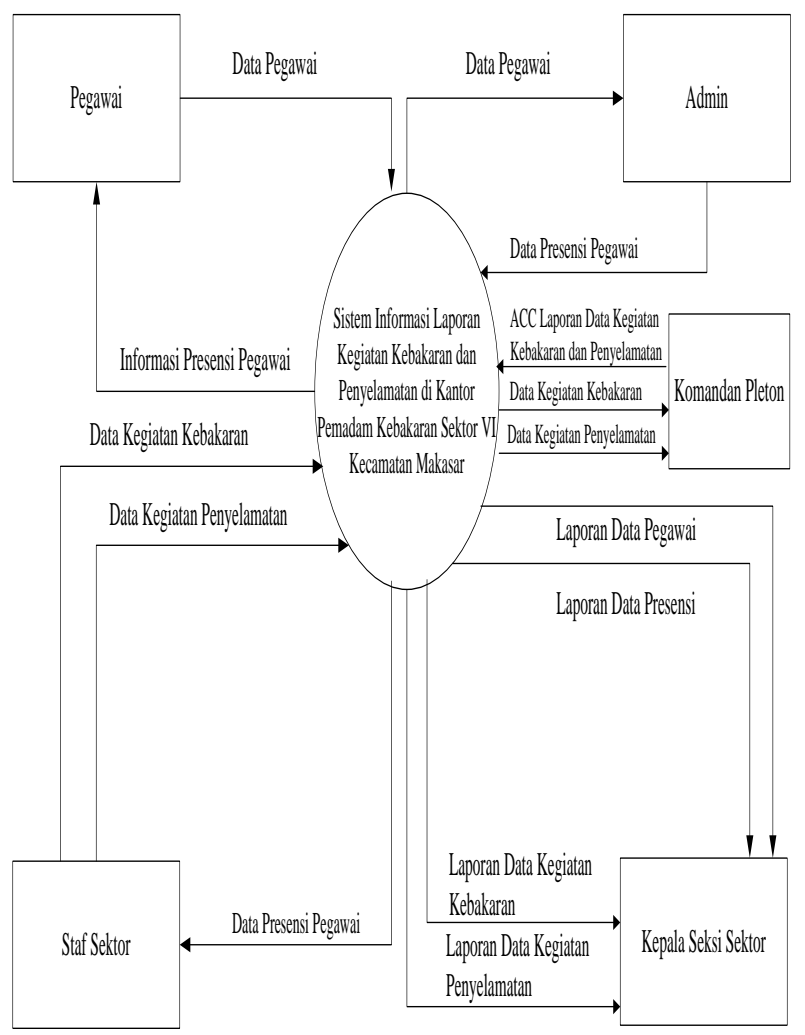

Gambar 1. Diagram Konteks

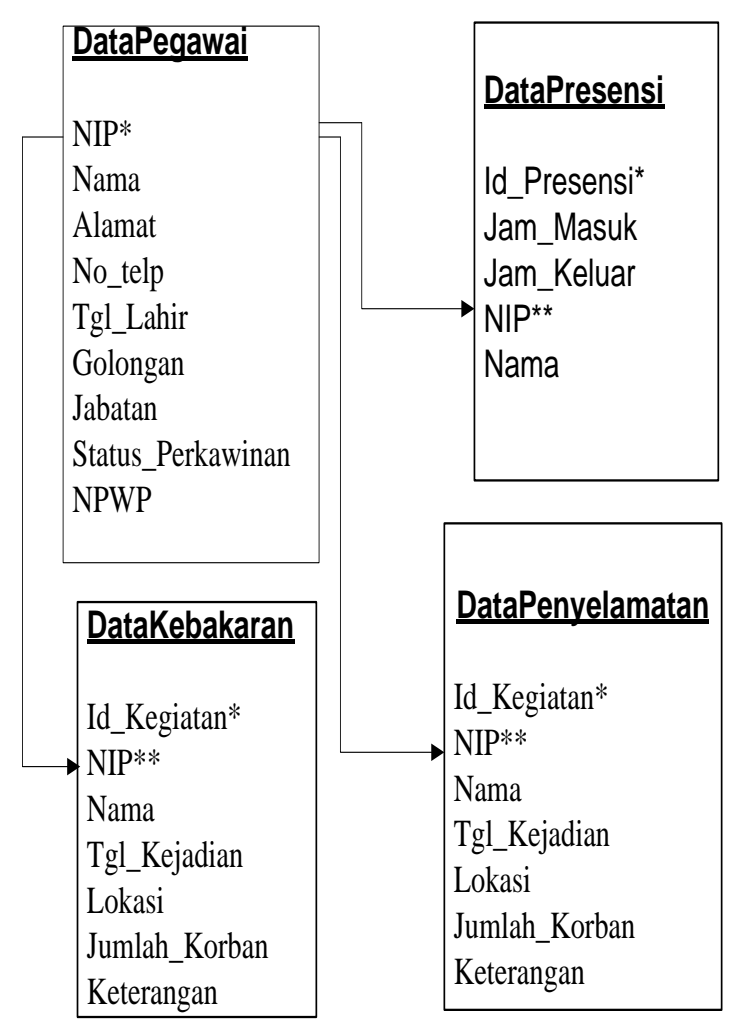

Gambar 2. Normalisasi 


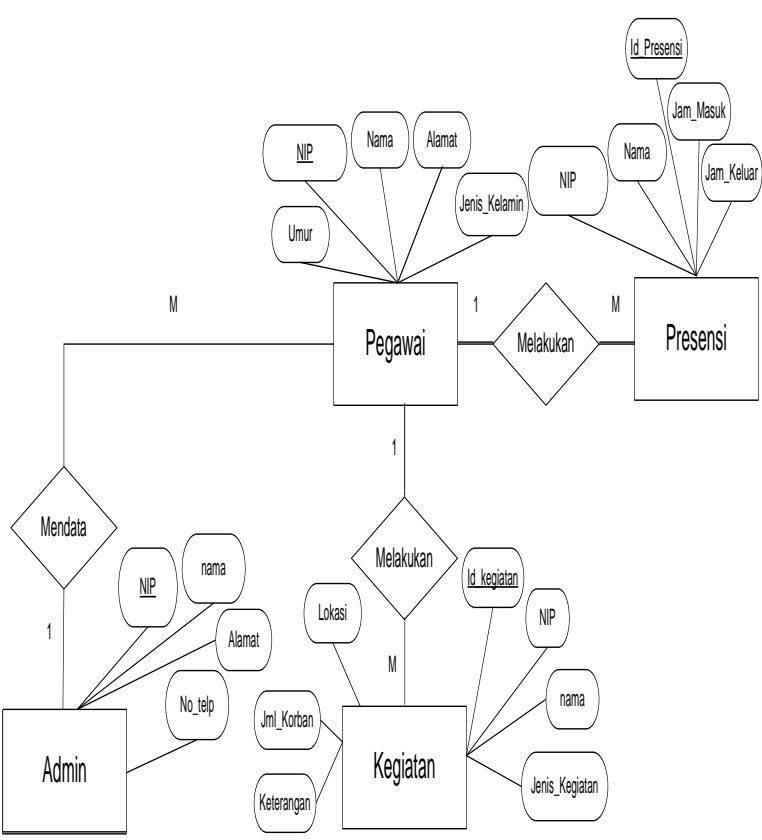

Gambar 3. ERD (Entity Relationship Diagram)

Berikut adalah tampilan layar dan hasil pengujian pada software program yang telah di buat dengan bahasa pemrograman Java.

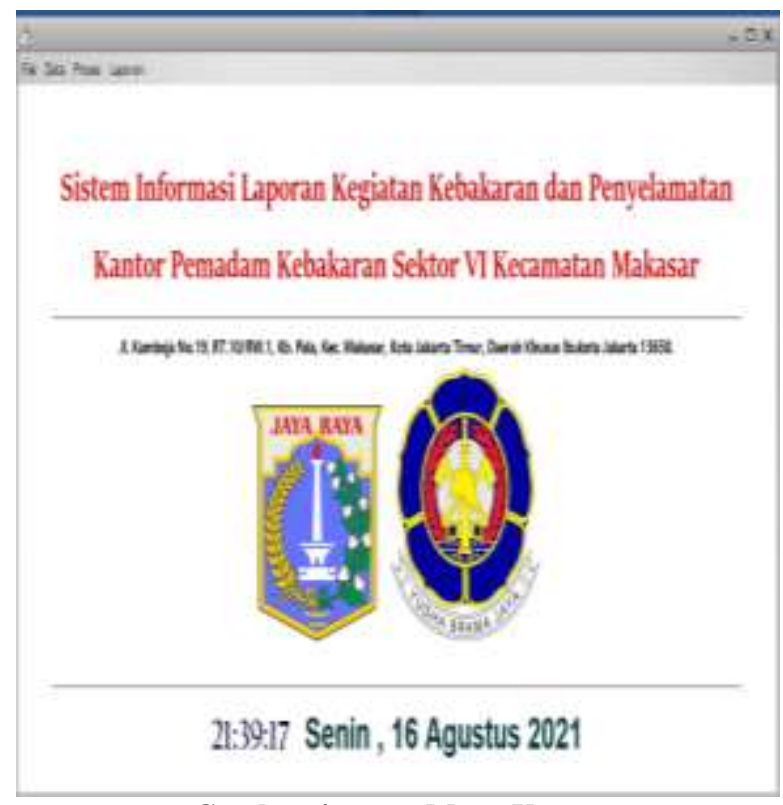

Gambar 4. Form Menu Utama

Layar di atas menampilkan tampilan Menu Utama pada Sistem Informasi Laporan Kegiatan Kebakaran dan Penyelamatan Kantor Pemadam Kebakaran Sektor VI Kecamatan Makasar. Pada layar utama tersedia menu bar yang terdiri dari master data yang digunakan untuk memasukkan data yang berkaitan dengan data pegawai, data presensi, data kegiatan kebakaran, data penyelamatan dan laporan-laporan.

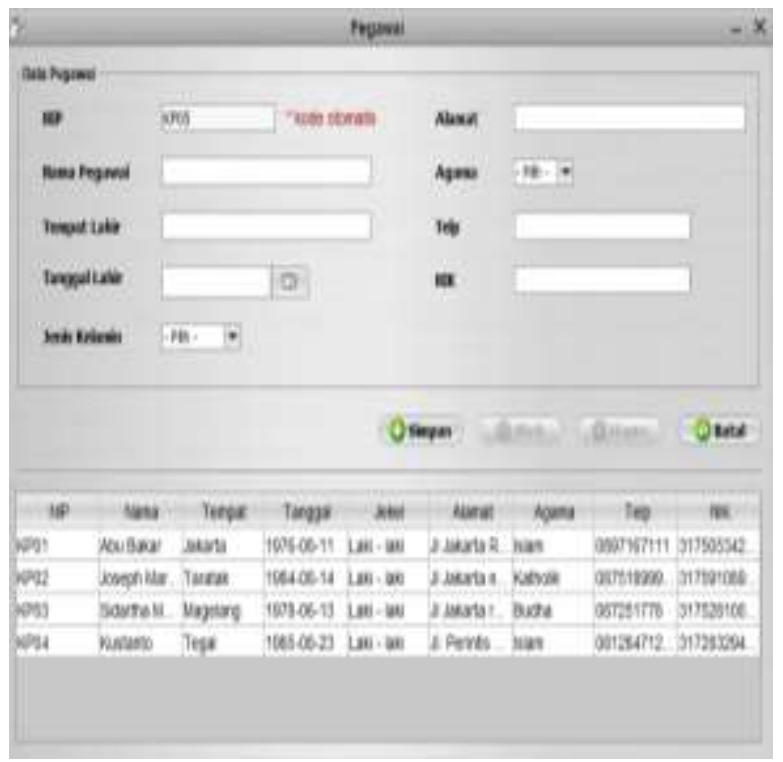

Gambar 5. Form Data Pegawai

Layar di atas menampilkan tampilan form data pegawai. Pada layar form data pegawai untuk meng-input data pegawai yang terdiri dari NIP, Nama Pegawai, Tempat Lahir, Tgl Lahir, Jenis Kelamin, Alamat, Agama, Telp dan NIK.

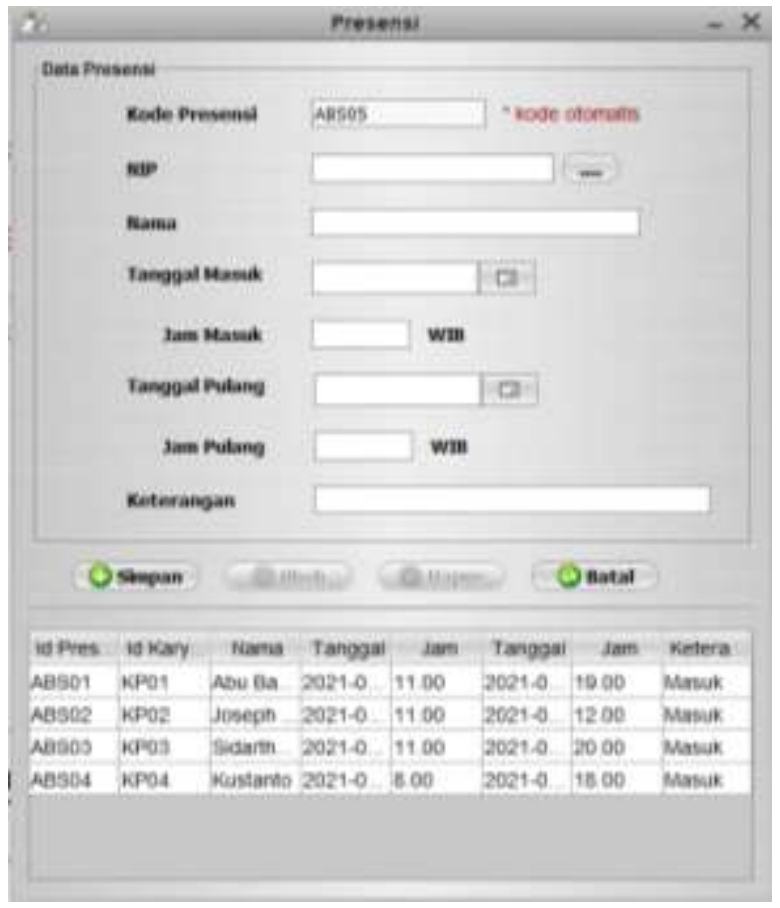

Gambar 6. Form Data Presensi 
Layar di atas menampilkan tampilan form data presensi. Pada layar form data presensi untuk meng-input data presensi yang terdiri dari Kode Presensi, NIP, Nama, Tanggal Masuk, Jam Masuk, Tanggal Pulang, Jam Pulang dan Keterangan.

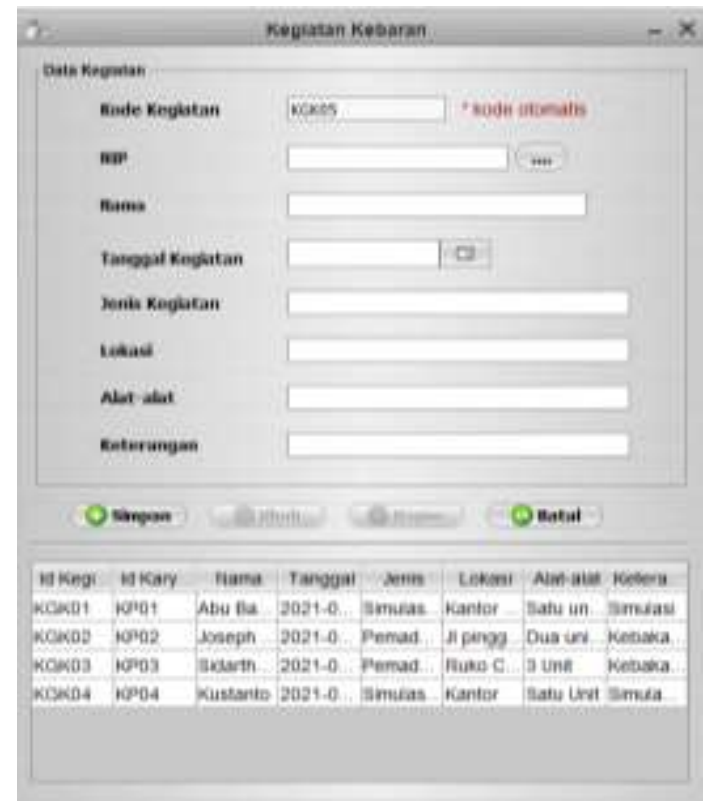

Gambar 7. Data Form Data Kegiatan Kebakaran

Layar di atas menampilkan tampilan form data kegiatan kebakaran. Pada layar form data kegiatan kebakaran untuk meng-input data kegiatan kebakaran yang terdiri dari Kode Kegiatan, NIP, Nama, Tanggal Kegiatan, Jenis Kegiatan, Lokasi, Alat-alat, dan Keterangan.

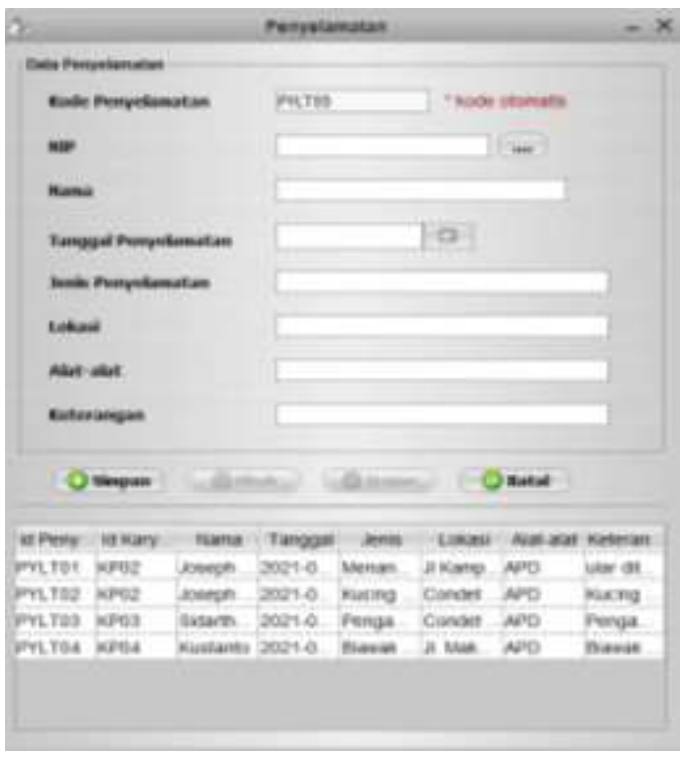

Gambar 8. Form Data Penyelamatan
Layar di atas menampilkan tampilan form data penyelamatan. Pada layar form data penyelamatan untuk meng-input data penyelamatan yang terdiri dari Kode Kegiatan, NIP, Nama, Tanggal Penyelamatan, Jenis Penyelamatan, Lokasi, Alatalat, dan Keterangan.

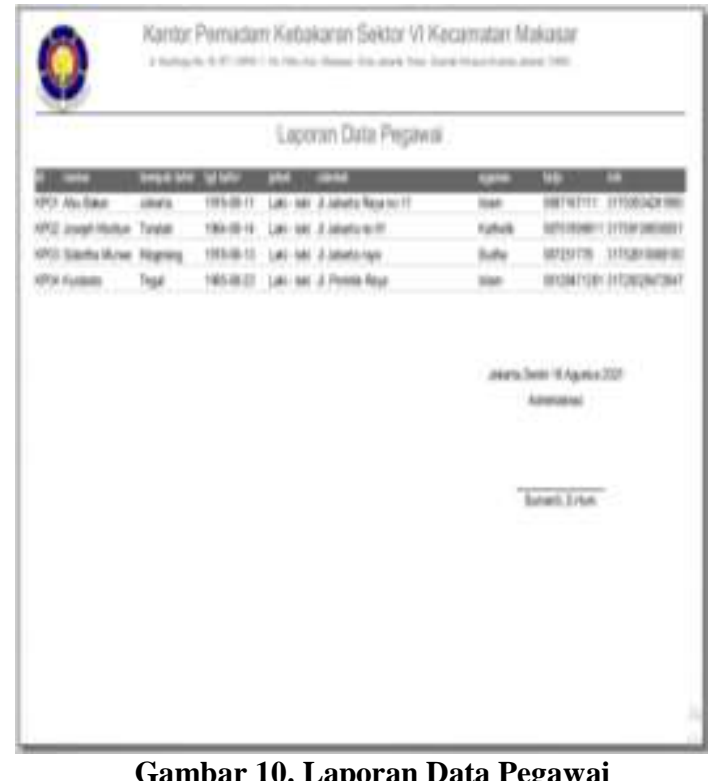

Layar di atas menampilkan tampilan form laporan data pegawai. Pada layar form data pegawai digunakan untuk mengecek laporan data pegawai terdiri NIP, Nama Pegawai, Tempat Lahir, Tgl Lahir, Jenis Kelamin, Alamat, Agama, Telp, NIK.

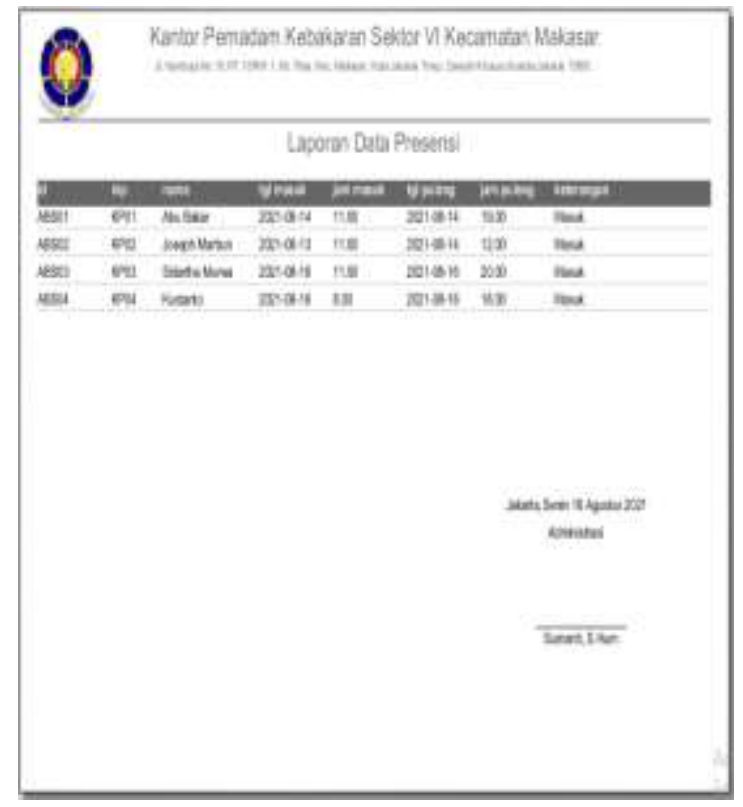

Gambar 11. Laporan Data Presensi

724 | Aplikasi Laporan Kebakaran dan Penyelamatan Kantor Pemadam Kebakaran Sektor VI Kecamatan Makasar 
Layar di atas menampilkan tampilan form laporan data presensi. Pada layar form data presensi digunakan untuk mengecek laporan data presensi terdiri Kode Presensi, NIP, Nama, Tanggal Masuk, Jam Masuk, Tanggal Pulang, Jam Pulang dan Keterangan.

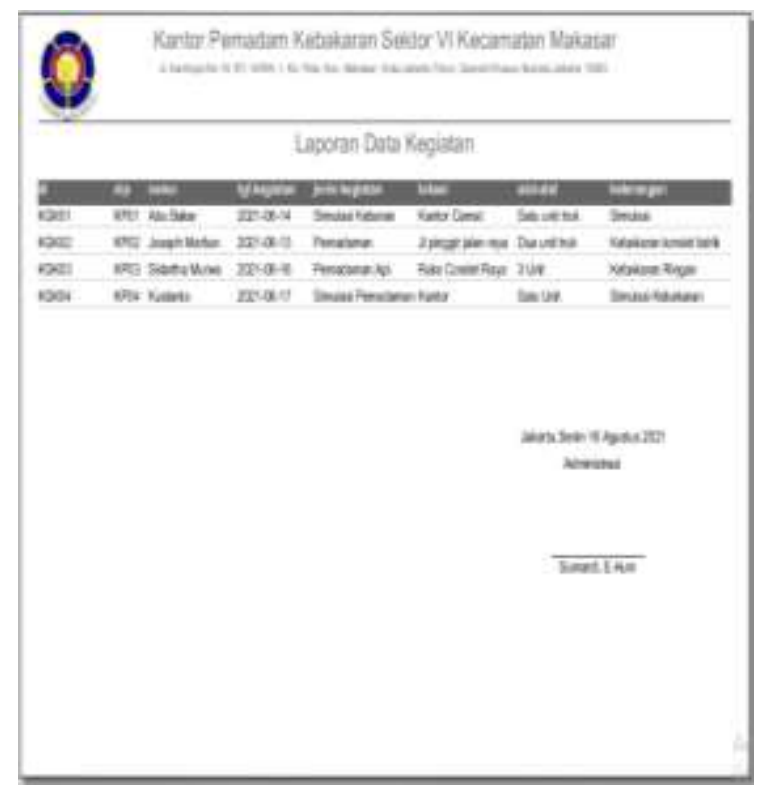

Gambar 12. Laporan Data Kegiatan Kebakaran

Layar di atas menampilkan tampilan form laporan data kegiatan kebakaran pada layar form data kegiatan kebakaran digunakan untuk mengecek laporan data kegiatan kebakaran terdiri Kode Kegiatan, NIP, Nama, Tanggal Kegiatan, Jenis Kegiatan, Lokasi, Alat-alat, dan Keterangan.

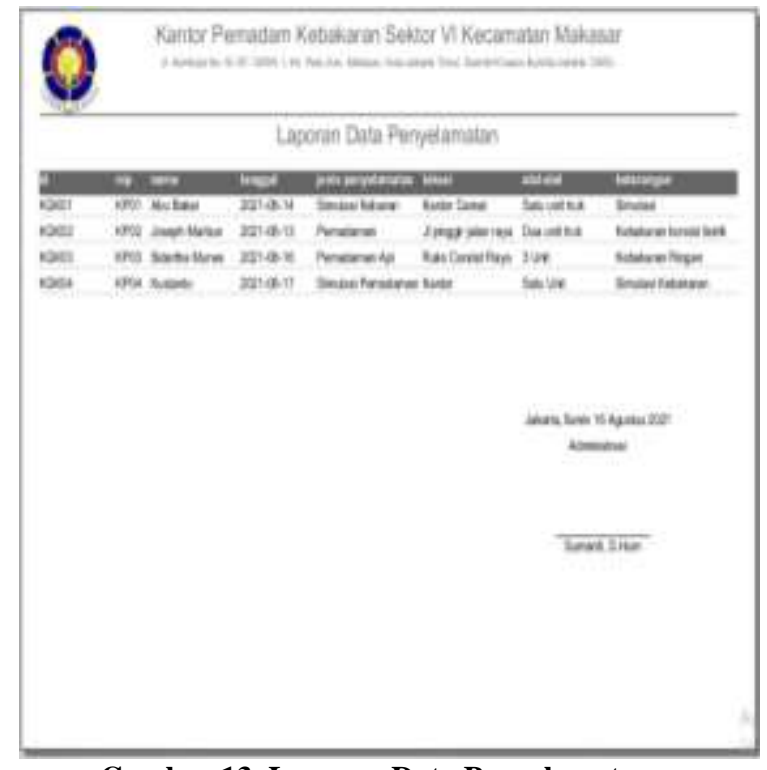

Gambar 13. Laporan Data Penyelamatan
Layar di atas menampilkan tampilan form laporan data penyelamatan pada layar form data penyelamatan digunakan untuk mengecek laporan data penyelamatan terdiri Kode Kegiatan, NIP, Nama, Tanggal Penyelamatan, Jenis Penyelamatan, Lokasi, Alat-alat, dan Keterangan.

\section{SIMPULAN DAN SARAN}

Aplikasi yang sudah dirancang dapat memproses pengolahan data laporan kegiatan kebakaran dan penyelamatan di Kantor Pemadam Kebakaran Sektor VI Kecamatan Makasar. Aplikasi pengolahan data laporan kegiatan kebakaran dan penyelamatan sudah terkomputerisasi sehingga menghasilkan laporan yang tersimpan dengan baik dan memberikan hasil secara cepat dan akurat.

Sarannya adalah sebelum aplikasi ini ujicoba, sebaiknya seluruh pihak yang terkait dalam sistem harus diberikan penjelasan dengan baik terlebih dahulu mengenai proses kerja aplikasi yang diterapkan sehingga tidak terjadi kekeliruan. Serta perlu dilakukan pelatihan penggunaan aplikasi tersebut terhadap pengurus yang terlibat dalam aplikasi ini, agar pengguna dapat mengetahui dan memahami cara kerja aplikasi yang baru.

\section{DAFTAR PUSTAKA}

Antisipasi, A., \& Jakarta, P. (2016). Sistem Reaksi Cepat Satgas Desa Dalam Pelaporan Kebakaran Lahan Dan Hutan Berbasis Android. Prosiding SNATIF, 3(1), 339-346.

Arrazy, S., Sunarsih, E., \& Rahmiwati, A. (2014). Penerapan Sistem Manajemen Keselamatan Kebakaran Di Rumah Sakit Dr. Sobirin Kabupaten Musi Rawas Tahun 2013. Jurnal Ilmu Kesehatan Masyarakat, 5(2), 103-111.

Fitriansyah, A. (2017). Sistem Informasi Pusat Data Dampak Kebakaran Hutan dan Lahan Berbasis Mobile Web di Provinsi Riau. Jurnal TEKNOSI, 03(01), 35-42.

Kebakaran, D. A. N. P., Kowara, R. A., Martiana, T., \& Keselamatan, D. (2017). Analisis Sistem Proteksi Kebakaran Sebagai Upaya Pencegahan Dan Penanggulangan Kebakaran (Studi di PT. PJB UP Brantas Malang). Jurnal Manajemen Kesehatan, 3(1), 70-85.

Prasojo, M. (2011). Pengantar Sistem Informasi 
Manajemen. bandung: CV. Remadja Karya.

Putra, N. (2011). Research and Development, Penelitian dan Pengembangan: Suatu Pengantar. Jakarta: PT Raja Grafindo Persada.

Satzinger, J. W., Jackson, R. B., Burd, S. D. (n.d.). System Analysis and Design in A Changing World. USA: Cengage Learning.

Sugiyono. (2016). Metode Penelitian Kuantitatif, Kualitatif dan $R \& D$. Bandung: PT Alfabet.

Sutabri, T. (2012). Analisis Sistem Informasi. Yogyakarta: Andi.

Tyoso, J. S. P. (2016). Sistem Informasi Manajemen. Yogyakarta: DeePublish. 